\title{
Las bibliotecas públicas híbridas en el marco de la Alfabetización Informacional
}

\author{
María Pinto*, Alejandro Uribe Tirado**
}

Resumen: Se presenta una reflexión crítica sobre la necesidad que las bibliotecas públicas respondan a las exigencias en colecciones y servicios que implica ser una biblioteca híbrida, específicamente en el desarrollo de programas de ALFIN que integren la multiplicidad de usuarios, las potencialidades de las herramientas Web $2.0 \mathrm{y}$ las oportunidades o amenazas según el apoyo gubernamental y/o social que reciben como espacios de cultura y educación en el contexto iberoamericano. Partiendo de la metodología documental centrada en el análisis de contenido de la literatura especializada, se toma como referencia tanto los principales hitos que han marcado el desarrollo de ALFIN en los últimos 30 años como las principales prestaciones de la Web 2.0, para ofrecer una selección de experiencias sobre acciones de formación desde algunas bibliotecas públicas iberoamericanas, analizando cómo están asumiendo la interrelación entre las competencias informáticas e informacionales y la Web 2.0, destacando los avances y los retos para afrontar las necesidades formativas, informativas y tecnológicas de los usuarios.

Palabras clave: Alfabetización Informacional, biblioteca pública, Web 2.0, ALFIN 2.0, Iberoamérica.

\section{Hybrid public libraries in the context of information literacy}

Abstracts: This paper puts forward a critical reflection on the need for public libraries to meet requirements for collections and services in order to become bybrid libraries, specifically in order to develop information literacy programs capable of integrating multiple users, the potential of Web 2.0 tools, and the opportunities or threats depending on governmental and/or social support they receive as cultural and educational spaces in the context of Ibero-America. Beginning with the documentary methodology of a content analysis of specialized literature, this paper then looks at the milestones marking the development of information literacy over the past 30 years as well as the main benefits of Web 2.0. The result is a selection of training experiences from various Ibero-American public libraries, analyzing how they are managing the relationship between the Web 2.0 and computer/information competencies, and highlighting the progress and challenges of meeting users' training, information and technology needs.

Keywords: Information literacy, public library, Web 2.0, InfoLit 2.0, Ibero-America.

\footnotetext{
* Universidad de Granada, Departamento de Información y Documentación.

Correo-e: mpinto@ugr.es

** Universidad de Antioquia, Escuela Interamericana de Bibliotecología.

Correo-e: auribe@bibliotecologia.udea.edu.co

Recibido: 09-12-2011; 2. ${ }^{\mathrm{a}}$ version: 28-02-2012; aceptado: 14-03-2012.
} 


\section{Introducción}

Las bibliotecas públicas (BP) son en estos momentos la tipología de unidad de información que más retos debe afrontar para responder tanto a las múltiples exigencias y necesidades de los usuarios y a los continuos cambios tecnológicos, como a los vaivenes políticos, económicos y sociales de los gobiernos e instituciones que soportan su crecimiento y sostenibilidad.

Por otro lado, asistimos a un cambio de paradigma en la biblioteca pública en tránsito hacia una biblioteca híbrida que afecta tanto a la gestión de sus colecciones como al desarrollo de sus espacios físicos y virtuales, y a los programas de formación, centrados especialmente en la alfabetización informacional (ALFIN). La biblioteca pública en comparación con la universitaria y la escolar tiene una mayor multiplicidad de usuarios a los que prestar servicios de formación tanto en competencias informáticas como informacionales (niños, jóvenes, adultos, personas de la tercera edad; nativos digitales, inmigrantes digitales; etc.) y por tanto, necesitan normalmente más recursos humanos, físicos y tecnológicos para afrontar esta realidad, de los que no siempre disponen, por lo que habitualmente se arrastran ciertas carencias iniciales que ralentizan las acciones y los logros.

Este artículo tiene como objetivo ofrecer una visión de la biblioteca pública en tránsito hacia la biblioteca híbrida y sus interrelaciones con las TIC (especialmente la Web 1.0 y 2.0) y con la alfabetización informacional, así como recoger algunos ejemplos representativos en el contexto iberoamericano y ofrecer una serie de recomendaciones para afrontar los siguientes interrogantes: ¿Cuál será el futuro de la ALFIN en las bibliotecas públicas?, ¿Será una seña de identidad clave para la biblioteca?, ¿Qué implicará no desarrollar programas de ALFIN?, ¿Cómo evolucionará el concepto en el contexto de las bibliotecas públicas?, ¿Con qué obstáculos se encontrará?, ¿Con qué ayudas?, etcétera.

\section{Biblioteca pública híbrida, Web 1.0, 2.0 y ALFIN}

Es importante definir qué entendemos por biblioteca pública híbrida y cuáles son sus interrelaciones con la Web 1.0, 2.0 y con la ALFIN.

La biblioteca pública híbrida es aquélla que posee colecciones impresas y digitales, que facilita el acceso a dichas colecciones y suministra servicios de información y programas de formación híbridos (presenciales, semipresenciales, mediados por TIC, en ambientes virtuales de aprendizaje, etc.), es decir, una formación en ALFIN híbrida, para así responder a las distintas necesidades y perfiles de los múltiples usuarios.

En lo relativo a programas de formación desde las bibliotecas públicas, es necesario tener presente que ese proceso de enseñanza-aprendizaje ha vivido un proceso evolutivo, de cambio, producido por la incorporación de las TIC (compu- 
tadores, Web 1.0, Web 2.0, etc.), por las transformaciones en los modelos educativos y en las teorías del aprendizaje y por la implementación de programas de ALFIN como se aprecia en la figura 1:

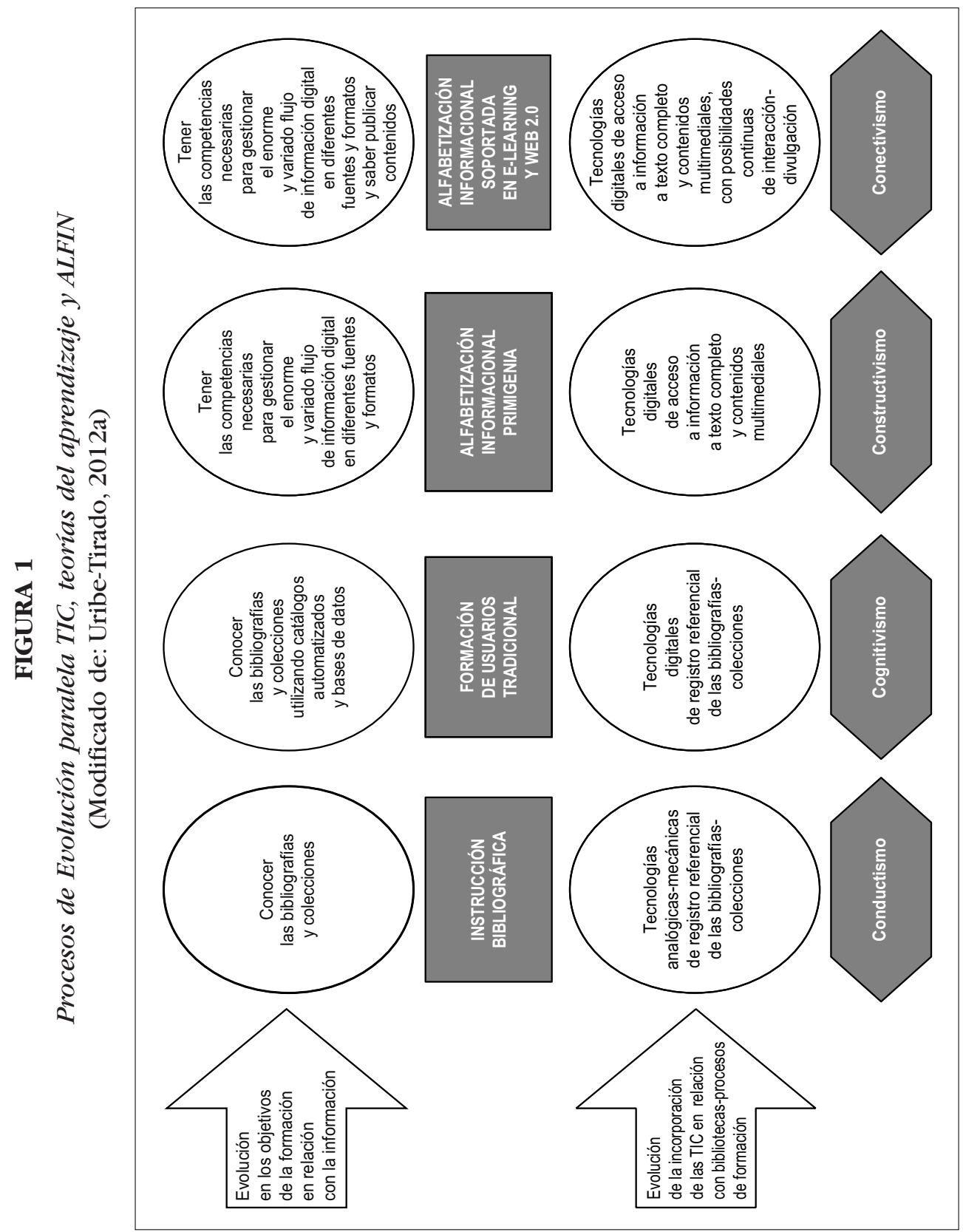


Esta propuesta de comprensión de la evolución de los procesos de formación desde las bibliotecas implica que se va avanzando hacia el concepto que denominamos e-ALFIN 2.0. Este se basa inicialmente en la conceptualización propuesta por González Fernández-Villavicencio (2008), y se representa desde nuestra concepción mediante la siguiente ecuación (figura 2):

\section{FIGURA 2}

Ecuación de e-ALFIN 2.0

(Adaptada de: González Fernández-Villavicencio, 2008)

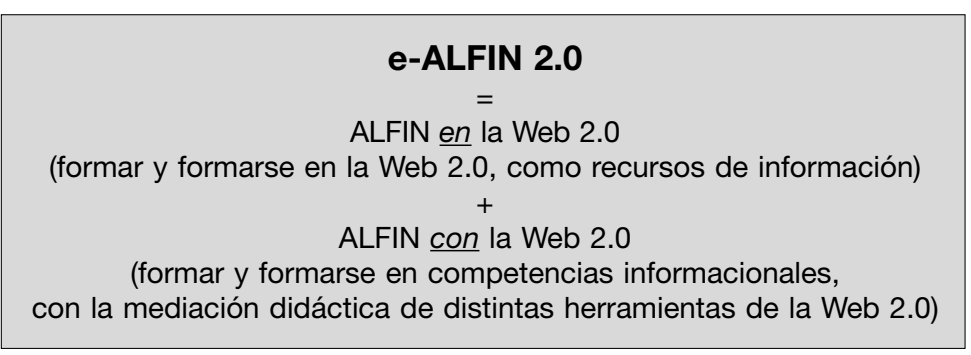

Cuando indicamos que la ALFIN debe caminar hacia una formación híbrida, esto no significa que se deba ofrecer solo mediante fuentes de información 2.0, sino que se puede usar esa modalidad en función de los usuarios, sus posibilidades y contextos. Como afirman Webber (2006) y Bruce y otros (2006), sigue estando vigente en ALFIN una formación que considera los aspectos convencionales (utilización de los servicios de la biblioteca), la formación competencial (aprendizaje de las competencias básicas como identificación de la necesidad de información, la búsqueda, localización y organización) y lo innovador (evaluación de recursos, uso ético y comunicación de la información a través de herramientas de la Web 2.0).

En este sentido coincidimos con Gómez-Hernández (2007, p.44) cuando dice que "la ALFIN no se limita a preparar para usar una institución o sus servicios, ni pretende que el usuario se adapte a nuestros criterios técnicos u organizativos, ni se queda meramente en la instrucción bibliográfica, en las habilidades de búsqueda y localización de la información. La ALFIN pretende o aspira a incluir competencias no trabajadas usualmente en la formación de usuarios: evaluación de los recursos, comprensión, utilización y comunicación de la información. Es decir, para usar la información en la toma de decisiones o generar conocimiento bay que entrar en habilidades cognitivas, e incluso en aspectos éticos. Muchas actividades de formación de usuarios serian aspectos parciales de la ALFIN, pero en función de las necesidades de los individuos, de las posibilidades del contexto o de la colaboración con otros mediadores en procesos de aprendizaje, deberemos ir más allá para incluir el uso reflexivo e intencional de la información para la creación de conocimiento". 


\section{Metodología}

La metodología de este trabajo es documental y se centra tanto en el análisis de los estudios previos sobre el tema, especialmente bibliométricos, como en el análisis de contenido por expertos de la literatura especializada y de los principales recursos digitales del proyecto ALFIN/Iberoamérica y de los sitios Web de las bibliotecas públicas iberoamericanas, utilizando herramientas de la Web 2.0.

La metodología se articuló en dos fases: por un parte, la identificación de los principales hitos internacionales de ALFIN, y por otra, su presencia en las bibliotecas públicas para identificar casos de interés.

\subsection{Hitos de ALFIN internacionales}

Este proceso evolutivo de la ALFIN puede ser analizado con más detalle si nos centramos en los hitos que en los últimos 30 años han determinado la aparición, crecimiento y posicionamiento de la alfabetización informacional como paradigma de la formación, tanto en las bibliotecas (Pinto y otros, 2008), como en la interacción curricular de profesores y bibliotecarios en los distintos niveles educativos.

Revisando la literatura sobre el tema, observamos que los estudios básicos sobre ALFIN se pueden agrupar en varias perspectivas: 1) bibliométrica, basada en los estudios cuantitativos sobre producción bibliográfica de ALFIN (Rader, 2002; Town, 2002; Marzal y Calzada, 2007; Pinto y otros, 2010; Pinto y otros, 2011, etc.); 2) interdisciplinar, centrada en el concepto evolutivo de la alfabetización informacional desde los enfoques lingüístico, conceptual y/o terminológico (Behrens, 1994; Cesarini, 2004; Bawden, 2001, 2002; Virkus, 2003, entre otros), y 3) contextual, basada en la aplicación y prácticas de ALFIN en determinados contextos geográficos (Spitzer y otros, 1998; Cuevas Cerveró, 2007; García Gómez y Díaz Grau, 2007; Lau, 2007; Basili, 2003, 2004, 2008, 2009; Grassian y Kaplowitz, 2009; etc.).

Desde nuestra visión amplia y transversal, destacamos cuatro categorías de hitos significativos para ALFIN, agrupados en modelos, estándares, normas y directrices, instrumentos de evaluación, y eventos-declaraciones ${ }^{1}$. La mayoría de los hitos recopilados han tenido su desarrollo y mayor impacto en las bibliotecas universitarias, donde la ALFIN ha alcanzado mayor madurez. No obstante, recogemos e identificamos también aquellos que han influido en el quehacer de la ALFIN en las bibliotecas públicas a nivel mundial (BP) (tabla I).

1 Estos hitos pueden consultarse en el sitio Web: http://alfincolombia.blogspot.com (Menú contextual derecho). 


\section{TABLA I}

Hitos internacionales de ALFIN y su influencia en bibliotecas públicas

\begin{tabular}{|c|c|}
\hline 1. & Modelos: \\
\hline & - 8 Ws of Information Inquiry-LAMB. \\
\hline & - The PLUS MODEL. \\
\hline & - Modelo Markless. \\
\hline & - Modelo de Stripling. \\
\hline & - Biblioteca escolar y competencia informacional-DURBAN (BP). \\
\hline & - Big Blue. Information Skills Training (BP). \\
\hline & - Big6 Skills. Information Problem-Solving Approach (BP). \\
\hline & - ISkills for an Electronic World. \\
\hline & - Search Process Model-KUHLTHAU (BP). \\
\hline & - Seven Faces of INFOLIT in Higher Education-BRUCE. \\
\hline & - Six Frames for INFOLIT Education-BRUCE et al. \\
\hline & - The Seven Pillars of INFOLIT model-SCONUL. \\
\hline & - Web-Based Information Searching-EDWARDS. \\
\hline & - Modelo INFOLITRANS. \\
\hline 2. & Estándares, normas y directrices: \\
\hline & - A National INFOLIT Framework (Scotland). \\
\hline & - AASL-AECT (BP). \\
\hline & - CAUL-ANZIL. \\
\hline & - DHI Ciudad Juárez. \\
\hline & - Directrices Internacionales para la ALFIN (BP). \\
\hline & - Indicadores de ALFIN (UNESCO) (BP). \\
\hline & - INFOLIT Competency Standard for Higher Education-ALA-ACRL. \\
\hline & - Competencias informáticas e informacionales en los estudios de grado. REBIUN. \\
\hline 3. & Instrumentos de evaluación: \\
\hline & - SAILS (BP). \\
\hline & - ETS' Information and Communication Assessment. \\
\hline & - Information-Seeking Skills Test (ISST). \\
\hline & - TRAILS. \\
\hline & - ALFIN-HUMASS. \\
\hline
\end{tabular}


TABLA I (Continuación)

4. Eventos-Declaraciones:

- Talleres Formación de Formadores ALFIN-UNESCO 2008-2009 (BP).

- Agenda para la investigación en instrucción bibliográfica y alfabetización informacional (ALFIN).

- Characteristics of Programs of Information Literacy that Illustrate Best Practices.

- Declaración de Alejandría (BP).

- Declaración de Praga (BP).

- Declaración de Toledo (BP).

- Declaración de Lima.

- Declaración de Paramillo.

- Declaración de Maceió.

- Declaración de Fes.

- Declaración de La Habana: 15 acciones de ALFIN desde Iberoamérica (BP).

- Final Reports of the UNESCO Training-the-Trainer.

- Hacia una universidad ALFIN.

- Informe: Estado del Arte ALFIN.

- Teacher Training Curricula for Media and INFOLIT.

\subsection{Influencia en las bibliotecas públicas iberoamericanas e identificación de casos}

Teniendo en cuenta esa identificación de hitos, así como la recopilación bibliográfica del Repositorio-Wiki ALFIN/Iberoamérica² ${ }^{2}$, de la sección de bibliotecas públicas del portal ALFARED 3 y del reciente monográfico sobre ALFIN compilado por Felicidad Campal (Veintitantas experiencias ALFIN..., 2012), se procedió a un proceso de análisis de contenido de los documentos recopilados (Anexo $1^{4}$ ), para así conocer cómo han influido los principios y la aplicación de ALFIN en las bibliotecas públicas iberoamericanas pudiendo identificar aquéllos casos más significativos que incluimos en el apartado 4.

${ }^{2}$ http://alfiniberoamerica.wikispaces.com/

3 http://www.alfared.org/page/bibliotecas-p-blicas/630

${ }^{4} \mathrm{El}$ Anexo 1 puede consultarse en: https://docs.google.com/open?id=0BweUYcipCswRYmR JMOdhM2RRckc0ZE9vNGo0b0 RVQQ 


\section{Resultados teórico-conceptuales}

Si analizamos y profundizamos en los hitos identificados, observamos que son las bibliotecas públicas las que deben realizar un mayor esfuerzo para desarrollar e implantar programas de ALFIN, con lo que ello supone de inversión de recursos.

Algo similar ocurre si nos adentramos en el uso de modelos, normas e instrumentos de evaluación, donde también deberán de afrontar un gran reto debido a la tipología de usuarios que ha de atender, lo que les obliga, o a generar una formación específica para los distintos grupos -niños y adolescentes (escolar), jóvenes (universitario), adultos (universitario y educación continua), personas de la tercera edad (educación continua)-, o al diseño de un modelo general de ALFIN que en la práctica se adecue a cada grupo poblacional según sus necesidades de información, empleando estrategias y contenidos específicos de formación-evaluación que faciliten la adquisición de las competencias informacionales.

De ahí, que implementar programas de ALFIN en las bibliotecas públicas suponga también trabajar en distintas estrategias para alcanzar en primera instancia una alfabetización digital (competencias digitales) si el grupo poblacional aún no las tiene adquiridas, y complementaria y paralelamente, avanzar en la formación de una ALFIN básica y 1.0 en tránsito hacia la e-ALFIN 2.0. Como estrategias de utilidad, centrados en las competencias informacionales, proponemos las siguientes:

1. Identificar las necesidades de información y el comportamiento informacional de cada uno de los principales grupos poblacionales (perfil de usuario) de la biblioteca.

2. Seleccionar un modelo de ALFIN integral que considere la adquisición de todas aquellas competencias clave relacionadas con el ciclo de la información.

3. Considerar las fuentes de información pertinentes según las necesidades de información y comportamientos de los distintos grupos poblacionales.

4. Ejemplificar según los intereses, los aprendizajes significativos, de cada grupo poblacional.

5. Utilizar la intermediación para el aprendizaje de las competencias según los conocimientos y experiencias previas y las preferencias de cada grupo poblacional, utilizando tanto la modalidad presencial como la virtual, o su combinación (blended learning).

6. Planificar tanto los aspectos administrativos y operativos como los pedagógicos y didácticos para avanzar hacia una biblioteca 2.0 que apuesta por una e-ALFIN 2.0 para los usuarios que lo requieran, en convivencia con otras formas mixtas teniendo en cuenta el paradigma de biblioteca pública híbrida. 
7. Revalorizar el rol activo que ha de tener la biblioteca pública como escenario relevante y fuente de oportunidades para fomentar el aprendizaje a lo largo de la vida, ayudando a la formación de los distintos grupos poblacionales, especialmente los más desfavorecidos y necesitados. La biblioteca debe fomentar la cohesión social en un contexto social multicultural, ofreciendo espacios integradores de comunicación y entornos de autoformación y desarrollo personal en el marco de la educación informal y no formal (Goulding, 2004).

8. Ofrecer un plan de iniciativas, actividades e indicadores de ALFIN (Pasadas-Ureña, 2006), que evidencien la rentabilidad social de la biblioteca pública y permitan comprobar las competencias logradas por los usuarios. ALFIN permite a las personas pasar de la dependencia respecto de los "intermediarios del conocimiento" a convertirse en "creadores de conocimiento".

A continuación ofrecemos algunos puntos clave de interés, encaminados a que toda biblioteca pública avance hacia la filosofía y la práctica de la e-ALFIN 2.0, para satisfacer a todos sus usuarios, tanto de los nativos como de los inmigrantes digitales (hacerlos "legalizados digitales").

\subsection{Decisiones y actitudes para un programa de e-ALFIN 2.0}

El concepto ALFIN 2.0 por analogía al término Web 2.0 (o de e-ALFIN 2.0 considerando el papel importante en este proceso del e-learning, como se representa en la figura 2), supone la translación de la filosofía y fundamentos de la Web social a los principios y a la práctica de la alfabetización informacional, pues en ALFIN también el usuario es el eje y motor de los distintos servicios y aprendizajes.

Las prestaciones de Web 2.0 pueden ser de utilidad en las bibliotecas públicas para múltiples fines:

- como herramienta para difundir sus servicios y sus actividades de formación;

- como estrategia de visibilidad e impacto en Internet, al alcance de cualquier usuario que frecuenta estos canales de comunicación;

- como forma innovadora para recabar información de los usuarios en relación con sus necesidades y carencias formativas e informativas;

- como vía de coparticipación de los usuarios, que se sientan parte de la biblioteca, involucrándolos en la creación de contenidos, en la propuesta de recursos y materiales formativos;

- como recurso y fuente para el aprendizaje de competencias y habilidades informacionales, de manera contextualizada e integrada en el quehacer diario; 
- como espacio para la reutilización de contenidos abiertos, pues muchos sitios permiten la utilización de su información para la generación de nuevos servicios;

- como procedimiento de innovación y mejora en el trabajo de los bibliotecarios, compartiendo nuevos métodos y nuevas ideas, contribuyendo de esta forma al aprovechamiento de la inteligencia colectiva;

- como cauce para la comunicación entre los profesionales, ya que ofrece la posibilidad de crear redes de trabajo e intercambiar experiencias.

La biblioteca pública debe tener presente que muchos de los servicios de la Web 2.0 se pueden utilizar también en otros dispositivos móviles distintos del ordenador, como la telefonía móvil inteligente y los dispositivos integrados con conexión a Internet, tipo tabletas, que permiten un doble uso informativo-formativo.

A su vez, la biblioteca pública de hoy día es el escenario adecuado para desarrollar programas de e-ALFIN 2.0 y abrir nuevas posibilidades de enseñanzaaprendizaje, nuevas formas de trabajar, y nuevos modos de participación e interacción para la ciudadanía. De esta manera se optimizarían las sinergias entre la biblioteca 2.0, la ALFIN y el e-learning para colaborar y fortalecer los procesos de formación competencial de los ciudadanos, relacionados con el acceso, uso y aprovechamiento de la información. Para acometer esta tarea con éxito, la biblioteca pública tiene que asumir que además de afrontar los crecientes cambios tecnológicos, ha de cambiar e innovar en los procesos, en las actitudes y en la manera de ofrecer sus servicios a los usuarios.

El desarrollo e implantación sistemática de programas de e-ALFIN 2.0 en la biblioteca y en general de programas de multialfabetización, podría satisfacer los siguientes objetivos:

- la formación de los ciudadanos no tendría barreras, podría ser ubicua e informal, fomentando la coparticipación e interacción.

- ayudaría a la generación de contenidos dinámicos y multimedia para apoyar esa formación, que se retroalimentaría con el concurso de los usuarios, al poder sugerir recursos, escribir comentarios, compartir opiniones, lecturas y experiencias...

- la biblioteca podría aumentar su visibilidad e impacto en el entorno, creando blogs temáticos que ofrezcan consejos, recursos e información de calidad.

\subsubsection{Elementos clave de un programa integrador de ALFIN}

Las bibliotecas públicas deberán contribuir hoy más que nunca al desarrollo de la alfabetización informacional en la ciudadanía y al fomento del aprendizaje a lo largo de la vida, actuando este último como vaso comunicante que interrelaciona y retroalimenta los distintos tipos de alfabetizaciones que una persona necesita en todas las edades y circunstancias. 
La necesidad de desarrollar acciones de alfabetización informacional como ya hemos señalado es palpable en nuestra sociedad actual, donde la biblioteca pública está adquiriendo progresivamente un papel protagonista, pasando a ser un centro plural de encuentro, de información, de formación y de inclusión, que contribuye al acceso democrático de la información. Sabemos que no es fácil establecer un modelo integrador para el desarrollo de un programa de ALFIN, de e-ALFIN 2.0 en la biblioteca pública, precisamente por la heterogeneidad de los usuarios y por el contexto de uso, pero sí es posible proponer unas recomendaciones generales para su diseño que contemplen los siguientes aspectos:

- El programa de ALFIN ha de tener una fundamentación pedagógica, social y aplicativa clara, previamente planificada y contrastada en función de los diversos grupos poblacionales que acuden a la biblioteca y de los distintos niveles culturales, sociales, formativos que tienen.

- Debe ser un programa integrador y a la vez modular, proactivo y dinámico que pueda anticiparse en la medida de lo posible a las necesidades cambiantes de nuestra sociedad plural.

- Debe ser colaborativo y abierto, que fomente tanto la implicación de los profesionales del centro, de los agentes culturales como de los usuarios, incorporando nuevas perspectivas en función de sus intereses.

- Ha de tener como meta a medio plazo, la formación continua de los profesionales de la biblioteca, especialmente en temas relacionados con las competencias informáticas e informacionales.

- Tanto la dirección como los profesionales de estas instituciones, han de estar muy comprometidos con sus respectivas funciones dentro de la agenda de desarrollo de la ALFIN.

- Enfatizar el fomento de la autonomía en el aprendizaje (aprendizaje centrado en el sujeto que aprende), incorporando la presencia del pensamiento crítico y la reflexión, ampliando el horizonte formativo hacia la alfabetización múltiple (entre otras, media, multimedia e intercultural).

- Incorporar un sistema riguroso de evaluación de ALFIN, tomando como punto de partida la filosofía de la autoevaluación para detectar carencias y poder abordarlas desde un espíritu de mejora constante.

- Asumir la necesaria labor cooperativa para el desarrollo de la biblioteca híbrida entre los diversos agentes que participan en el proceso: personal bibliotecario, comunidad múltiple de usuarios, instituciones públicas de enseñanza, asociaciones culturales, etc. Para ello resulta fundamental el establecimiento de alianzas y la inclusión de actividades colaborativas con otras bibliotecas públicas así como el apoyo en las bibliotecas universitarias que en el contexto mundial (Stripling, 2006) o iberoamericano (UribeTirado, 2012b) son las que tienen más avances y pueden hacer importantes aportaciones con las debidas adaptaciones contextuales. 


\subsubsection{El empoderamiento del usuario}

La calidad total es una apuesta reciente en el marco de las bibliotecas públicas, y su implementación conlleva la mejora sistemática y continua de sus productos y servicios, con el fin de conseguir la satisfacción de los clientes, el logro de nuevas oportunidades para el desarrollo institucional, la mejora en el uso de los recursos, la reducción de costes y la optimización de la imagen de la biblioteca como organización que impacta en su entorno, mejorando la calidad de vida de los ciudadanos. La apuesta por la calidad es la inversión más inteligente a medio y largo plazo que una biblioteca puede hacer, pues supone:

- La adopción de una filosofía basada en la gestión del cambio en todos los ámbitos de la biblioteca, adoptando la mejora continua como actitud y el enfoque al usuario como estrategia.

- Una aproximación sistemática y holística a los problemas de gestión de la biblioteca, cuyo objetivo principal es el logro de un estado de máxima satisfacción generalizada: de clientes-usuarios, de empleados y de la ciudadanía en general.

La satisfacción de los usuarios se ha transformado en la meta final de los servicios bibliotecarios y su empoderamiento en una exigencia actual, al considerar al usuario como parte del sistema, especialmente en el entorno de biblioteca 2.0. Cada vez más los usuarios creen ser independientes en el acceso y uso de la información, tienen una cultura tecnológica avanzada (en muchos casos, pero no en todos), son consumidores y productores de información, tienden a compartir, difundir e intercambiar todo tipo de información y conocimiento, son pioneros en la utilización de herramientas y aplicaciones en línea, tienen capacidad de comunicación, por tanto, son usuarios que aportan, difunden, comparten, colaboran y consumen información (Li y otros, 2009).

\subsubsection{La innovación, factor clave para la supervivencia}

El año 2009 ha sido considerado como el Año Europeo de la Creatividad y la Innovación, y la Unión Europea ha promocionado estos conceptos desde una perspectiva instrumental, como motores de crecimiento económico y de desarrollo social. Habitualmente, la creatividad se asocia con lo artístico, mientras que la innovación evoca lo tecnológico y lo industrial. Pero la biblioteca pública como centro social y cultural de la comunidad ha de sumarse también a las exigencias de la innovación, entendida desde un enfoque amplio y holístico, tanto tecnológico como principalmente humanístico, siendo el capital humano el pilar esencial para el desarrollo, la promoción y el impacto de los servicios bibliotecarios en la comunidad y en el entorno. Por esto es importante, que el concepto de innovación y creatividad cale entre los bibliotecarios, y que en consonancia con las nuevas exigencias del cambio, apuesten por una formación competencial ade- 
cuada para afrontar los nuevos modelos de gestión del conocimiento y del aprendizaje.

Innovar no es sólo hacer cosas distintas, sino hacer cosas mejores. Innovar es aplicar nuevas ideas y pensamientos creativos realizados por mentes desafiantes y visionarias, que consiguen introducir variaciones como resultados de procesos de evaluación y ajuste, cambiando la forma de competir dentro de la organización. La innovación se ha convertido en un requerimiento actual para el mantenimiento del ciclo de vida de productos, procesos y servicios de la biblioteca pública. Implica la novedad o transformación que se introduce en ellos, según las necesidades de los usuarios, el progreso de las tecnologías, la rapidez de producción y la reducción de costos. El proceso de innovación representa una oportunidad de cambio estratégico de la biblioteca para poder hacer frente a la competitividad global y convertirse en una puerta abierta al conocimiento abierto, sin barreras ni limitaciones espaciales ni temporales, en continuo crecimiento y con la posibilidad de ser enriquecido, modificado y/o personalizado a la carta. Es la nueva dimensión de la biblioteca invisible, una entelequia que existe en el espacio virtual y que actúa como guía y asesora de todos aquellos que a ella se dirigen.

En el transcurso de los últimos años han ido surgiendo en el seno de la biblioteca pública una serie de innovaciones que se definen dependiendo de la implicación y el efecto de sus resultados en el usuario final. Mientras unas han sido menores, pues no modifican la esencia del producto/servicio (p. ej los OPAC), otras han transformado la condición misma de estos, creando la necesidad del dominio de nuevas competencias como, por ejemplo, el uso masivo de Internet para la búsqueda de información, el auge de las herramientas de la Web social o el desarrollo de colecciones multimedia. Algunas de estas innovaciones han generado nuevos modelos de negocio, basados en el uso de nuevas tecnologías emergentes, como la telefonía móvil inteligente, los e-readers, etc., con lo que esto supone de cambio de estrategia en el acceso y uso de las colecciones, en la definición de nuevos productos y en el diseño de nuevos servicios, con alto valor agregado y para consumo directo. En este sentido, destacamos ciertas iniciativas de interés en el marco de las bibliotecas públicas, como el desarrollo de la biblioteca digital, el acceso a contenidos abiertos, el uso de los libros electrónicos, el préstamo de e-readers... A veces, estas novedades implican el dominio de nuevas competencias y habilidades, especialmente informacionales-digitales, hecho que la biblioteca tendrá que afrontar para potenciar un uso eficaz y eficiente de la información y de los recursos.

La innovación desde la biblioteca pública debe estar enfocada esencialmente al desarrollo de nuevos servicios y estrategias que faciliten lograr un cambio en la manera en que profesionales y ciudadanos se relacionan con la información y el conocimiento, con el fin de lograr los siguientes cambios: en los objetivos trazados para el cumplimiento de la misión; en la proyección e impacto de los servicios informacionales para la vida diaria; en las relaciones que establece la biblioteca con el resto de entidades locales, culturales y educativas; en los pro- 
cesos formativos que se desarrollan desde la biblioteca, que deberán estar más orientados a la evaluación y uso crítico de la información.

\subsubsection{La formación en alfabetización múltiple como meta: cultura informacional, mejora de la calidad de vida, bienestar social, inclusión social}

Las bibliotecas públicas desempeñaron en el pasado una función educativa, que se fue diluyendo al desarrollarse los sistemas educativos estatales, y su lugar fue ocupado por el desarrollo de colecciones que a veces reflejaban más los intereses de los bibliotecarios responsables que los de los usuarios.

De cualquier forma, el impacto de las TIC en las actividades de la vida diaria, profesional y de ocio del ciudadano, y las carencias formativas que tienen muchas personas junto a la precariedad de medios para acceder a la información en igualdad de condiciones, ha llevado a los poderes públicos, a la administración y a las bibliotecas a rediseñar su misión, sus metas y sus funciones, incorporando nuevos conocimientos y habilidades que ofrecen la alfabetización informacional, considerada como objeto de atención preferente en la Declaración de Praga (UNESCO, 2003), donde se propuso su inclusión en la Década de la Alfabetización de las Naciones Unidas 2003-2012 (ONU, 2000) como prerrequisito para participar eficazmente en la Sociedad de la Información, permitiendo su acceso y reduciendo la brecha digital dentro y entre países, así como promocionando los valores de tolerancia y comprensión mutua a través del uso de la información en contextos multiculturales y multilingües (Declaración de Alejandría. UNESCO, 2005).

Como recoge el Seminario-Declaración de Toledo (Ministerio de Cultura, 2006), la biblioteca pública ha de colaborar en esta educación documental de los ciudadanos, diseñando actividades de formación eficaces y coordinadas con las instituciones educativas. Esta alfabetización ha de ser múltiple, global e integradora, que armonice las distintas facetas alfabetizadoras necesarias en la sociedad de la información y del conocimiento: lecto-escritora, informacional, digital, multimedia, intercultural, emocional...

En este sentido, las líneas de investigación emergentes en ALFIN se relacionan con la reeducación y la formación a lo largo de la vida, con la alfabetización multimedia y digital, con el desarrollo de modelos e instrumentos de medición, con la definición de indicadores comparables, con la formación competencial de los propios bibliotecarios... (ACR/ALA, 2003; SCONUL, 2004; CILIP, 2004; Webber, 2006; Hilbun y Akin, 2007; Gómez-Hernández y PasadasUreña, 2007; Catts y Lau, 2008; Pinto y otros, 2008; Gómez-Hernández, 2009; Pinto, 2010; Pinto y Uribe, 2011; entre otros).

A modo de orientación, ofrecemos algunas propuestas de acción para una alfabetización múltiple en el marco de las bibliotecas públicas (Pinto y otros, 2009): 


\section{TABLA II}

Propuestas de acción para una alfabetización múltiple

\begin{tabular}{|c|c|}
\hline $\begin{array}{c}\text { ALFABETIZACIÓN } \\
\text { BÁSICA }\end{array}$ & $\begin{array}{l}\text { - Aprovechar las potencialidades de la Web } 2.0 \text { para mejorar la lec- } \\
\text { tura y la escritura, enfatizando la lectura social. } \\
\text { - Diseñar e implementar iniciativas integradoras, que vinculen la lec- } \\
\text { toescritura con el resto de alfabetizaciones (informacional, multi- } \\
\text { media, intercultural). }\end{array}$ \\
\hline $\begin{array}{l}\text { ALFABETIZACIÓN } \\
\text { INFORMACIONAL }\end{array}$ & $\begin{array}{l}\text { - Formar en el uso estratégico y crítico de Internet. } \\
\text { - Formar en técnicas de evaluación de la calidad, enseñando a re- } \\
\text { conocer las fuentes de información de calidad. } \\
\text { - Reforzar la formación en infocompetencias, especialmente en aque- } \\
\text { llas relacionadas con los aspectos cognitivos de la información: } \\
\text { analizar, sintetizar, esquematizar y usar la información. }\end{array}$ \\
\hline $\begin{array}{l}\text { ALFABETIZACIÓN } \\
\text { MULTIMEDIA }\end{array}$ & $\begin{array}{l}\text { - Aprovechar las potencialidades de los materiales audiovisuales } \\
\text { como recurso formativo y facilitar su uso. } \\
\text { - Contribuir a la capacitación multimedia del usuario, ofreciendo con- } \\
\text { tenidos adecuados y formación, aprovechando el potencial del e- } \\
\text { aprendizaje. }\end{array}$ \\
\hline $\begin{array}{l}\text { ALFABETIZACIÓN } \\
\text { INTERCULTURAL }\end{array}$ & $\begin{array}{l}\text { - Fomentar el uso de la biblioteca pública entre los colectivos mi- } \\
\text { noritarios, estableciendo relaciones con los agentes locales. } \\
\text { - Impulsar la adquisición de recursos específicos que atiendan las } \\
\text { necesidades informativas y formativas de una sociedad multicultu- } \\
\text { ral. } \\
\text { - Ofertar programas multilingües de formación de usuarios y reali- } \\
\text { zar versiones multilingües de los folletos informativos sobre los ser- } \\
\text { vicios de la biblioteca. }\end{array}$ \\
\hline
\end{tabular}

En este sentido, los profesionales de la biblioteca pública han de comprender la necesidad de actuar como buenos gestores para formar y motivar a los distintos colectivos de usuarios, para lograr una alfabetización integral que les capacite como ciudadanos del siglo xxI.

\subsubsection{La cultura social como fenómeno}

El paradigma de la tecnología y la educación 2.0 genera mejoras en el usuario al brindar un espacio virtual con nuevos recursos y posibilidades para enriquecer su proceso de aprendizaje y de participación. En el fondo, la biblioteca que usa tecnologías de la Web 2.0 ha de esforzarse en ofrecer a sus usuarios una formación en ALFIN acorde con estas potencialidades, de manera que el usuario pueda aprender haciendo -bajo el principio de ensayo/error-, aprender interactuando -gracias a la hipertextualidad del contenido y al intercambio de ideas con el resto de usuarios-; aprender buscando -sabiendo cómo y dónde buscar los contenidos- y aprender compartiendo -experiencias y conocimientos. 
Cuando hablamos de cultura social nos referimos al uso de la filosofía y de determinadas tecnologías de la Web 2.0, como software social, rss, mashups, etiquetado, webblogs, wiki... y a la aplicación de una determinada actitud en el diseño y consumo de los servicios Web, basada en los principios de compartir, de interactuar, de reutilizar, de intervención del usuario como fuente de información y de aprovechamiento de la inteligencia compartida para beneficio de todos.

En este sentido, las innovaciones tecnológicas asociadas con la Web social -organizada bajo la premisa de la participación y el conocimiento colectivo- han revitalizado aún más la función bibliotecaria y ha convertido a la biblioteca en la plataforma idónea para el uso de herramientas 2.0, tanto tecnológicas como alfabetizadoras. Es por ello clave que la biblioteca pública se convierta en una biblioteca 2.0, para que en sus programas de formación ofrezca múltiples opciones y estrategias, que combinen lo analógico y lo digital, es decir, que sea una formación en ALFIN híbrida, que pueda llegar hasta la e-ALFIN 2.0.

Considerando todo lo dicho anteriormente, es importante resaltar algunas buenas prácticas de bibliotecas públicas que están alcanzando esa perspectiva 2.0 para sus servicios de información generales, y especialmente para sus servicios de formación.

\section{Resultados aplicados}

Los resultados teórico-conceptuales presentados en el apartado anterior nos han servido de base para la identificación de las buenas prácticas.

\subsection{Buenas prácticas: biblioteca híbrida y e-ALFIN 2.0 en el contexto iberoamericano}

Tras la consulta de la bibliografía especializada (ver nota iv) y de los distintos recursos Web existentes sobre bibliotecas 2.0 y ALFIN a nivel mundial 5 e iberoamericano $^{6}$, que permiten identificar valiosas iniciativas de desarrollo, recogemos algunas buenas prácticas recientes de bibliotecas públicas que realizan procesos de formación en ALFIN empleando los recursos de la Web social y del e-learning como paso hacia la e-ALFIN 2.0.

Conviene anotar que no presentamos una evaluación de estos casos ni un análisis de sus resultados, sino más bien la identificación de buenas prácticas en los diferentes países iberoamericanos que sirvan de referencia para otras biblio-

5 INFOLIT Global: http://www.infolitglobal.net/directory/en/home - Information Literacy meets Library 2.0: http://infolitlib20.blogspot.com/

${ }^{6}$ Mapa Biblioteca 2.0: http://bit.ly/brJ3QT - Bibliotecas y ALFIN 2.0: http://www.netvibes.com/ nievesglez\#General - Wiki bibliotecas y Web social: http://biblio20.pbworks.com/w/page/2478 3712/00_Inicio - Mapa ALFIN/Iberoamérica: http://bit.ly/9hu80u

Rev. Esp. Doc. Cient., N. ${ }^{\circ}$ Monográfico, 136-168, 2012. ISSN: 0210-0614. doi: 10.3989/redc.2012.mono.980 
tecas públicas. Como evidencia desde la literatura especializada (Lau, 2007; Uribe-Tirado 2012b) en esta modalidad de biblioteca, comparada con la biblioteca universitaria, son muchos menos los desarrollos y casos, por lo que hay que enfatizar que las bibliotecas públicas todavía tienen que realizar grandes esfuerzos para desarrollar programas de ALFIN en sentido general y más específicamente de e-ALFIN 2.0. Por otro lado, algunas bibliotecas públicas han priorizado la formación en alfabetización digital, apostando por una mayor incorporación de la Web 2.0 (fuentes de información y medios de divulgación y aprendizaje), más que en la alfabetización informacional, por ahora o como paso previo.

\subsection{España}

\subsubsection{Biblioteca Pública de Salamanca}

Entre las diferentes actividades formativas destacan las relacionadas con la ALFIN como apoyo tanto a la educación formal en los diferentes niveles educativos (primaria, secundaria...) como a la búsqueda de empleo, impulsando para ello un programa formativo-tutorial (http://www.alfared.org/node/862) sobre diversos temas relacionados con las competencias informacionales, informáticas, comunicacionales e idiomáticas: como redactar un currículum vitae y una carta de presentación, cómo y donde buscar empleo, como afrontar el proceso de selección y afrontar una entrevista de trabajo, algunos recursos para la autoformación en TIC e idiomas.

Este tutorial ha sido una iniciativa del Grupo de Trabajo de ALFIN del CCB (GTALFIN), que ha tenido un gran desarrollo desde la biblioteca pública de Salamanca, con sus respectivas adaptaciones contextuales (http://www.jcyl.es/web/ jcyl/pr/_/Bibliotecas/Page/BibliotecasPlantilla DetalleContenido/1190354141715/ Biblioteca/1284197071629/_?asm=jcyl\&paginaID=1190354141715), considerando la retroalimentación de los participantes, que han permitido excelentes resultados: "Desde la primera sesión los asistentes nos plantearon la necesidad de seleccionar información verídica y útil entre toda la que se puede encontrar en Internet. Por ello, en la última sesión de cada formación además de la evaluación del Tutorial, incluimos algunas pautas básicas sobre cómo evaluar la información en Internet. La formación se completó con la entrega de una Guía de Empleo que titulamos "Con TE de Trabajo y Empleo". Esta guía reunía recursos propios de la biblioteca y una actualizada selección de recursos en Internet sobre empresas que ofrecen empleo, las mejores técnicas para encontrarlo, las claves para montar una empresa, cómo superar una entrevista o la forma de redactar correctamente un buen currículum. (Campal García y otros, 2012).

Este tutorial, elaborado desde el GTALFIN, a su vez, está siendo utilizado (como matriz) en más lugares, con las adaptaciones respectivas de cada biblioteca como es el caso de la Biblioteca Pública de Cuenca, entre otras. Igualmen- 
te, otros trabajos semejantes, cuya temática es la formación en competencias informacionales para la adquisición de empleo, han venido realizándose en otras bibliotecas públicas españolas con el aporte de otros materiales y recursos, como la Biblioteca Salvador Estrem i Fa (Vilanova, 2012); las bibliotecas de la Red de Bibliotecas Municipales de la provincia de Barcelona (Alvarez Massó, 2012); la Biblioteca Regional de Murcia (Castillo Fernández, 2012) y la Biblioteca Regional de Tarragona (Saumell Calaf y otros, 2012), etcétera.

\subsubsection{Biblioteca Municipal de Peñaranda de Bracamonte}

Esta biblioteca que forma parte del Centro de Desarrollo Sociocultural de la Fundación Germán Sánchez Ruipérez en Peñaranda de Bracamonte (CDS), ha desarrollado diferentes acciones formativas (http://cds.fundaciongsr.com/story. php?id=157) que poco a poco han ido evolucionando de la formación de usuarios tradicional (solo los servicios de la biblioteca) y de la alfabetización digital (aprender a utilizar instrumentalmente las TIC) a programas y acciones integrales centradas en la ALFIN 2.0, como el programa InFormar o los siguientes cursos: sobre Webquest; El libro electrónico y sus aplicaciones bibliotecarias; Contenidos y servicios para dispositivos móviles en bibliotecas; La pizarra digital en el día a día de la biblioteca infantil; Clubes de lectura en la nube, entre otros.

\subsubsection{Bibliotecas Públicas de Tarragona}

Desde esta red se coordinan todas las acciones formativas que realizan las bibliotecas públicas de Tarragona, que en el caso de ALFIN tiene una trayectoria de varios años (Saumell Calaf, 2006; Saumell y otros, 2012). Esta formación se concreta en tres acciones generales:

- Visitas guiadas para grupos de usuarios, con el propósito de explicar cómo funcionan los servicios de la biblioteca y como utilizar los recursos.

- Visitas escolares para difundir los servicios que ofrece la biblioteca, promover el hábito de lectura y explicar a los estudiantes cómo usar de forma adecuada los recursos.

- Formación en nuevas tecnologias.

La mediación de esta formación se consigue usando tanto el modelo convencional como los recursos de la Web, integrando de esta forma el modelo de biblioteca 2.0 con los postulados de e-ALFIN 2.0 (http://www.netvibes.com/bibliotequestarragona\#BLOCS_I_WEB_DE_LES_BIBLIOTEQUES_P\%C3\%9ABLIQUES_DE_TARR).

Igualmente, se destacan dentro de esta Red, casos concretos como el de la Biblioteca Pública de Tarragona y su trabajo de formación en competencias informacionales para la búsqueda de empleo y el de la Biblioteca Marcel.Li Domingo de Tortosa y su trabajo con personas con discapacidad intelectual, especí- 
ficamente sus acciones encaminadas a la "actividad de investigación" (Prades Ginovart, 2012), además de su trabajo de formación en competencias informacionales hacia jóvenes en interrelación con las instituciones educativas (http://www.bibliotecamarcellidomingo.blogspot.com/search/label/foramci\%C3\% B3\%20usuaris).

\subsubsection{Biblioteca Pública Municipal de Andorra «Juan Martín Sauras»}

Al igual que el caso anterior, desde esta biblioteca pública se ha creado un espacio propio desde una herramienta Web 2.0 como Netvibes (http://www.netvibes.com/biblioteca62\# FORMACION_DE_USUARIO). Puede observarse en este espacio 2.0 cómo se abordan las distintas actividades en ALFIN y ALFIN 2.0, que incorpora tanto los aspectos educativos como las necesidades cotidianas de información. Destacan las denominaciones singulares que dan a varios de sus cursos, tutoriales y acciones formativas: conoce la biblioteca, aprende en la biblioteca, la biblioteca digital, fuentes de información, taller de búsqueda de empleo, formación de usuario en las bibliotecas escolares, la Web 2.0, la biblioteca 2.0, seguridad y legalidad en Internet, tutorial biblioteca digital, cumpleaños de Maisy, redes sociales, prepararse para viajar, introducción a Internet y libros en la red.

\subsubsection{Bibliotecas Públicas de Galicia}

La Red de bibliotecas públicas de la comunidad gallega incluye las bibliotecas de las cuatro provincias. Algunas de estas bibliotecas han realizado avances destacados para pasar de la formación de usuarios tradicional a una formación desde el paradigma de ALFIN y los recursos de la Web 2.0 como fuentes informativas y mediaciones formativas. Son los casos de la Biblioteca Pública de Lugo (http://rbgalicia.xunta.es/lugo/index.php?subApartado=57) y de Santiago de Compostela (http://rbgalicia.xunta.es/santiago/), donde destaca la formación a los padres para orientar a sus hijos en competencias informacionales en Internet, o el uso de diferentes medios para acceder a la información. Aunque aún se pone mayor énfasis en las competencias informáticas, se va avanzando hacia la formación en las competencias informacionales como podemos observar en algunos trípticos (http://rbgalicia.xunta.es/santiago/descargas/1305103493.pdf).

\subsubsection{Biblioteca Regional de Murcia}

Esta biblioteca es un buen ejemplo de la importancia que una biblioteca pública debe dar a la Web 2.0 sin negar la información, servicios y formación analógicos, y acercándose al modelo de biblioteca híbrida. Esa relevancia de lo 2.0 se evidencia en el propio portal, con secciones como E-biblioteca y Web 2.0 (http://www.bibliotecaregional.carm.es/Biblioteca/faces/br-e-biblioteca), y Zona joven, que ofrecen información sobre la formación en competencias informáti- 
cas e informacionales. Sobresale la importancia concedida a la biblioteca como apoyo en la búsqueda de empleo y las competencias que esto implica (Biblioteca punto de empleo: http://www.bibliotecaregional.carm.es/Biblioteca/faces/ br-biblioteca-punto-empleo). Su interés por aprovechar la Web 2.0 como referente divulgativo y formativo, evidenciado por ejemplo en la creación y recopilación en un espacio en YouTube (http://www.youtube.com/watch?v=DKL6dJVmi4\&feature=channel_video_title).

A su vez, llama mucho la atención en el caso de esta biblioteca, que tiene una trayectoria importante en la formación en ALFIN (Peñalver Martínez y Gallo León, 2006), que influencia a las otras 15 bibliotecas de la Red de Bibliotecas Públicas de la Región de Murcia, con el programa: "¿Qué sabes? Ven a la biblioteca y cuéntalo: proyecto de formación colaborativa" (http://www.bibliotecaregional.carm.es/ Biblioteca/faces/br-proyecto-que-sabes), que busca formar en temáticas específicas de interés y relacionarlas luego con la formación propia en competencias informacionales: "las bibliotecas tienen muchos y muy buenos usuarios, y queremos aprovechar ese potencial de conocimiento para compartirlo con el resto de ciudadanos y con nuestro personal. "Si eres muy bueno en alguna actividad, disciplina o afición, tienes capacidad de transmitir y te apetece divulgar tus saberes, ponemos a tu disposición nuestras instalaciones para que vengas y nos lo cuentes"... Asimismo, se anima a los usuarios a que sugieran temas de su interés que desearían que alguien afrontase. Son los llamados "temas en busca de autor", que se publicitan a la espera de que alguien con conocimiento en la materia se anime a abordarlos".

\subsubsection{Biblioteca de Illescas (Toledo)}

Aunque presenta una oferta formativa convencional en competencias informáticas e informacionales, esta biblioteca destaca por la amplia oferta formativa desde una biblioteca para abordar las necesidades de información-formación de la vida cotidiana. Como indican las pautas Calimera retomando lo dicho en el informe ALFIN del Grupo de Trabajo de Alfabetización Informacional del Consejo de Cooperación Bibliotecaria (2009): "Desde la biblioteca se pueden organizan igualmente algunas de las siguientes actividades que fomentan el aprendizaje, como proponen las Pautas Calimera (2005) y como veremos en el resultado del análisis desarrollado en las BP: talleres música, fomento de la lectura mediante el préstamo de libros, clubes de lectura, encuentros con autores y facilitando lecturas adecuadas para los lectores principiantes, talleres de lectura, talleres de escritura y creatividad, herramientas de selección de libros basadas en la Web, estudios y curiosidades locales: consultas sobre literatura, las investigaciones genealógicas y sobre la historia de casas y edificios, nombres de las calles, bistorias y particularidades de la localidad". En esta biblioteca la formación de usuarios se complementa con los denominados Cursos de Cultura (http://www.bibliotecadeillescas.com/pdf/cursos_cultura_11.pdf). 


\subsubsection{Bibliotecas de Barcelona}

Esta red constituida por más de 30 bibliotecas públicas (http://w110.bcn.cat/ portal/site/Biblioteques/) ofrece una oferta formativa donde claramente se trabajan las competencias informáticas y se van dando paso a las informacionales y a las demás necesidades de información-formación que desde una biblioteca pública se pueden resolver (http://s2.puntxarxa.org/cbb/cursos/llista_cursos.php) apoyados en algunos casos en plataformas de aprendizaje como el LMS Moodle (http://biblioteques.fias.cat/), el uso de videotutoriales, etcétera.

Destacan sus esfuerzos por apoyar la integración, desde la perspectiva multicultural que implica la ALFIN, ofreciendo diferentes cursos y actividades formativas como los idiomas, los trámites administrativos o la búsqueda de un sitio dónde vivir, empleo, etc. (http://w3.bcn.es/V51/Home/V51HomeLinkPl/0,3989, 171935332_3317927052,00.html), además de formación-información relacionada con las artes y la literatura, implicando al mismo tiempo las competencias informacionales, literarias, comunicacionales y lingüísticas (http://bit.ly/fsHko5).

\subsubsection{Bibliotecas Públicas de la Comunidad de Madrid}

Algunas bibliotecas públicas de la Comunidad de Madrid han realizado una labor en pro de las competencias informacionales utilizando diferentes programas y estrategias. Es el caso de la Biblioteca Joaquín Leguina que ha realizado diversos cursos informativos sobre Madrid: "Fuentes de información sobre Madrid y su Región", para iniciarse en el estudio o investigación sobre Madrid, tanto para universitarios como para aficionados. Se repasan las fuentes bibliográficas, documentales y digitales sobre historia, arte y patrimonio, geografía, economía y estadística, además de presentarse los principales archivos y bibliotecas con fondos madrileños; "Madrid, historia de una ciudad milenaria", en el que se estudia la historia de la ciudad de Madrid, organizado en colaboración con el Centro de Documentación y Estudios para la Historia de Madrid-Universidad Autónoma de Madrid; y "Grandes peliculas y Madrid en el cine", centrado en el estudio de las grandes películas del celuloide como El acorazado "Potemkin", Octubre, Ciudadano Kaine, Manhattan, y en aquellas otras españolas y extranjeras que hayan tomado como plató las calles de Madrid (http://www.madrid.org/cs/Satellite?c= CM_InfPractica_FA\&cid=1142604956159\&idTema $=1142598542211$ \&language $=$ es\& pagename $=$ ComunidadMadrid $\% 2 F E s t r u c t u r a \& p i d=1273078188154 \& \mathrm{pv}=114262729$ 2308).

Mencionaremos también el caso de la Biblioteca Municipal de Chapinería y su trabajo de formar en competencias informacionales para el uso de la administración electrónica, dirigido a todos sus usuarios aprovechando un recurso Web 2.0 como Netvibes: (http://www.netvibes.com/bibliochapi\#EMIGRACI\% C3\%93N_Y_EMPLEO). 


\subsubsection{Red de Bibliotecas Públicas de Andalucía}

Desde la comunidad de Andalucía, en los últimos años se han ido realizando diferentes proyectos para lograr la implementación de ALFIN, de ALFIN 2.0 y de e-ALFIN 2.0 en el marco de las bibliotecas públicas. Destacamos estos tres trabajos: ALBA, DAMI y ACD.

El plan ALBA (http://planalba.pbworks.com/w/page/48363934/Contenidos\%20Plan\%20Alba) tiene como propósito ofrecer formación teórica y práctica sobre competencias informáticas e informacionales. El proyecto describe claramente el diagnóstico y las propuestas que lo guían lo cual es un importante avance (http://www.juntadeandalucia.es/cultura/Web/html/sites/consejeria/areas/biblioteca/Galerias/Adjuntos/Plan_ALBA_29_09_11.pdf).

Este programa ha logrado capacitar a más de 600 bibliotecarios en estas competencias, lo cual equivale a una tercera parte de este colectivo en la Red de Bibliotecas Públicas Andaluzas (Ortega Vaquero y González Fernández-Villavicencio, 2012).

A su vez, otras de las acciones concretas de este programa que favorecerán poco a poco el crecimiento de la e-ALFIN 2.0 en este contexto son la promoción de buenas prácticas de formación en competencias digitales, que sirvan de impulso para otras bibliotecas (Banco de Aplicaciones del Plan ALBA) y la creación y actualización de una Wiki/Repositorio de objetos de aprendizaje que sirvan de apoyo a las actividades formativas que deben generarse tras el proceso formativo inicial.

La propuesta DAMI (Diploma Andaluz de Manejo de Información) es otro espacio formativo de los bibliotecarios andaluces para crecer en sus competencias informacionales. Destaca la aportación de la Biblioteca Provincial de Huelva (http://www.juntadeandalucia.es/cultura/opencms/export/bibliotecas/bibhuelva/servicios/formusuario.html).

El programa ACD (Andalucía Compromiso Digital) busca apoyar la adquisición de competencias digitales entre la población andaluza en colaboración con la biblioteca provincial de Sevilla para el desarrollo de cursos como: administración electrónica, uso sano y responsable de las TIC por parte de los menores, introducción a los medios sociales de comunicación y colaboración, redes sociales y principales plataformas social media para compartir: utilización y gestión. En todos ellos se hace evidente la importancia de la Web 2.0 (http://www.juntadeandalucia.es/cultura/opencms/export/bibliotecas/bibsevilla/activbiblio/Actividades_alfabetizacion_digital.html). 


\subsection{Otros países iberoamericanos}

\subsubsection{Bibliotecas Públicas de Rosario (Argentina)}

Desde esta red, que cuenta con el apoyo de la Secretaría de Cultura y Educación de la municipalidad de Rosario, se presenta la ALFIN como un servicio muy destacado. El programa incluye lo que podría denominarse formación de usuarios tradicional (presencial-analógica) pero incorpora otras acciones formativas que le llevan a un alcance más de lo que implica la alfabetización informacional usando como estrategia "charlas informativas" y cursos de informática y Web 2.0. Se evidencia claridad en la conceptualización y desarrollo de las competencias informacionales consideradas como se expresa directamente desde su sitio Web (http://www.rosariocultura.gob.ar/escuelas-y-bibliotecas/biblioteca-argentina-dr.-juan-alvarez/alfabetizacion-informacional).

\subsubsection{Centro de Documentación Virtual Instituto Nacional de Formación Docente-Biblioteca Nacional del Maestro -BNM- (Argentina)}

Lo primero que debemos indicar en este caso es que aunque directamente no va dirigido a los usuarios, queremos presentarlo, como en algunos otros casos del contexto español, por el hecho de destacar que la implementación y crecimiento de ALFIN en las bibliotecas públicas depende del crecimiento de las competencias de los bibliotecarios y profesores, para que así puedan lograr una mejor cualificación de su capital humano que redunde en beneficio de los usuarios.

En este sentido, las bibliotecas necesitan una reorientación para acceder a colecciones documentales a través de los servicios y recursos de Internet, y a los materiales docentes. Como señalan las directrices IFLA/UNESCO para el desarrollo del servicio de bibliotecas, éstas han de ser impulsoras en los centros educativos de un programa específico de aprendizaje en el uso de la información, desarrollando actividades para que el estudiante conozca la biblioteca, su espacio, sus servicios y sus recursos de manera coordinada con las actividades que se realicen en relación con el uso de las nuevas tecnologías.

Por ello el CEDOC, en coordinación con la Biblioteca Nacional del Maestro -BNM-, como se indica desde su sitio web (http://cedoc.infd.edu.ar/index.cgi?w Accion=news\&wid_news $=142 \& w i d$ seccion=\&wid_item): apoya con recursos $y$ servicios al bibliotecario para el desarrollo de actividades donde se aprenden los contenidos referidos a la localización y recuperación de la información en bibliotecas y en Internet, poniendo un especial interés en la metodología investigadora, las características de las fuentes de información, las herramientas de búsqueda y los criterios de valoración más destacados.

Cabe destacar que el elemento más importante en este proceso es el apoyo y la acción educativa del profesor como guía y mediador, que encuentra en la 
biblioteca un centro de recursos para el aprendizaje, y en el bibliotecario, apoyo y acompañamiento.

\subsubsection{DIBAM/BIBLIOREDES (Chile)}

Desde la Dirección de Bibliotecas y Archivos de Chile y específicamente desde el programa BIBLIOREDES que coordina las bibliotecas públicas chilenas, se realiza un programa de formación continua que abarca diferentes estrategias formativas, una de las más destacadas es la formación de los usuarios tanto de manera tradicional como utilizando las herramientas de la Web 2.0 y plataformas de aprendizaje en línea como Moodle, asumiendo la e-ALFIN 2.0 (http://moodle.biblioredes.cl/course/category.php?id=10). Desde esta plataforma se ofrece una formación que incluye cursos tanto sobre competencias informáticas como las informacionales: búsqueda eficiente de la información, cómo publicar contenido y compartirlo en la Web 2.0, redes sociales en la Web 2.0, construcción de blogs, introducción a la Web 2.0, tramites en linea, ortografía y redacción para la Web. Esta experiencia formativa en ALFIN desde una perspectiva 2.0, se ha divulgado de diferentes formas donde se presenta el modelo de formación asumido desde este programa de bibliotecas públicas chilenas (http://www.slideshare.net/p_pacheco/alfin-en-bibliotecas-pblicas-chilenas-modelo).

\subsubsection{BIBLIORED (Colombia)}

La Red de Bibliotecas de Bogotá (BIBLIORED) tiene entre sus servicios clave la "Formación de Usuarios". Dentro de este programa incluyen una oferta formativa que abarca varias competencias integradas en la sociedad actual: competencias informacionales, informáticas y en idiomas extranjeros, que denominan: alfabetización informacional, inglés para niños, club de amigos de la biblioteca, inducción a la biblioteca y ruta informática. En relación con la alfabetización informacional, afirman que es un programa en el que se desarrollan las destrezas y habilidades para identificar, localizar, evaluar, organizar, crear, utilizar y comunicar con eficacia la información requerida para afrontar los problemas o las necesidades informativas que se presentan en la vida cotidiana. Desde esta perspectiva en los últimos años han ido integrando en la formación las prestaciones de la Web 2.0 (Fino Garzón, 2010; Fino Garzón y Valderrama Espejo, 2010). Esta experiencia ha sido guía de otras experiencias aún en proceso de construcción en bibliotecas públicas de Colombia, liderando programas sobre la temática (http://alfincolombia.blogspot.com/2010/10/encuentro-de-alfabetizacion.html) y participando en eventos internacionales sobre ALFIN (http://alfin.uncu.edu.ar/ presentaciones/Dia2/Universidad-Lasalle-Jornadas ALFIN.pptx). 


\subsubsection{Bibliotecas Municipales de Oeiras (Portugal)}

Esta red de bibliotecas de esta localidad de Portugal viene realizando un trabajo continuo en el desarrollo y crecimiento de ALFIN desde inicios de la primera década del siglo xxi (Correia y Teixeira, 2003; Calixto 2003, Amândio, 2007, 2009). Desde el sitio Web oficial de esta localidad, se remite a una información básica sobre las bibliotecas públicas, pero desde allí se puede tener acceso a un espacio blog desde el cual se da cuenta a todos los usuarios del quehacer de las bibliotecas. En concreto, en lo referente a alfabetización informacional, se encuentra una sección: http://oeiras-a-ler.blogspot.com/search/label/Infoliteracia en la cual se reportan importantes actividades realizadas los últimos 6 años. Entre esas actividades, y aún vigentes, se destacan los curso-taller para la búsqueda de empleo "Pesquisa de Emprego", además los de: "Iniciação à Internet e Pesquisa de Informação", "Uma Incrível Aventura à Volta do Mundo com o Google Earth" y "Internet Segura". Todas estas actividades formativas desde esta red de bibliotecas buscan como el mismo programa indica: "apresenta uma oferta diversificada de formação e ações "Infoliteracia" destinadas à aprendizagem das literacias digitais e de informação nas modalidades de acesso, avaliação, aplicação e organização em diferentes contextos".

En resumen, hemos descrito brevemente algunos casos relacionados con la promoción de ALFIN, ALFIN 2.0 y e-ALFIN 2.0, a lo que podemos sumar otras iniciativas como las siguientes: Biblioteca Pública de Cuenca (España), Biblioteca Pública de Leganés (España), Biblioteca Pública de Pozuelo (España), Biblioteca de Castilla-La Mancha (España), Biblioteca de Muskiz (España), Bibliotecas de Colsubsidio (Colombia), Servicio de Información Local de Comfenalco-Antioquia (Colombia), Bibliotecas Públicas Periféricas (Perú), Sistema de Bibliotecas Públicas de Costa Rica (Costa Rica), etcétera.

\section{El futuro de ALFIN en las bibliotecas públicas}

Finalmente queremos abordar el futuro de ALFIN en las bibliotecas públicas iberoamericanas con algunas recomendaciones que sirvan de prospectiva para visualizar hacia dónde se encaminan los derroteros y el desarrollo de ALFIN.

La implantación de programas e iniciativas de ALFIN, ALFIN 2.0 o e-ALFIN 2.0 en las bibliotecas públicas tiene que afrontar algunos retos relacionados tanto con aspectos estratégicos, como organizativos, económicos, funcionales y profesionales. Para ello, ofreceremos algunas recomendaciones de interés:

- La promoción e implantación de programas alfabetización informacional debe ser una cuestión de política educativa y cultural, que afecte a todos los niveles educativos y sectores de la sociedad, de manera que se pueda mejorar la escasa concienciación por parte de los responsables políticos y 
técnicos acerca de la necesidad de implantar programas y acciones a corto y medio plazo.

- Saber diferenciar los principios y elementos de la formación en competencias informáticas y en competencias informacionales, ya que en los casos revisados en la literatura especializada (Anexo 1) algunas experiencias denominadas de alfabetización informacional eran realmente de alfabetización informática o digital, dejando al margen todos los aspectos referidos a la gestión y uso de la información.

- Necesidad de combinar el desarrollo de programas de alfabetización digital (competencias informáticas) con la creación de programas propiamente de alfabetización informacional (competencias informacionales), para que se trabajen ambas competencias en todos los grupos de usuarios de la biblioteca pública según sus necesidades, teniendo presente las potencialidades que en ambas formaciones ofrece la Web 2.0 y el e-learning.

- Necesidad de una norma y/o guía para la evaluación de la alfabetización informacional en entornos de educación no formal e informal como las bibliotecas públicas (Gómez-Hernández y Pasadas-Ureña, 2007).

- Necesidad de una mayor capacitación y formación competencial de los profesionales que trabajan en bibliotecas públicas, con programas de formación de formadores para que a su vez puedan mejorar su formación y colaborar con el profesorado de los distintos niveles educativos.

- Mejora de la sensibilización, del espíritu de cooperación y de la visión estratégica de muchos profesionales que trabajan en bibliotecas públicas, sobre las aportaciones y valores de alfabetización informacional para el desarrollo competencial y personal de la ciudadanía.

- Fomento de la formación de los profesionales para la creación de materiales y contenidos digitales pedagógicos para el aprendizaje de la alfabetización informacional, que incluya según el nivel y grado de dificultad, distintos tipos de actividades, solución de problemas informacionales, juegos, etc. Sería recomendable crear objetos de aprendizaje transferibles para distintos niveles de aprendizaje y distintos perfiles de usuarios. Es decir, que las mediaciones de la formación sean híbridas: presenciales, semipresenciales (blended learning), totalmente virtuales (de autoaprendizaje) según los requerimientos, facilidades y potencialidades de los usuarios mismos y que pueda ofrecer la biblioteca, y que consideren diferentes ritmos, estilos y didácticas de enseñanza-aprendizaje (e-ALFIN 2.0).

- Una actitud proactiva para lograr mayor dotación de recursos económicos, materiales, tecnológicos y personales.

- Fomento de la cultura de la planificación y evaluación de las competencias informacionales en el marco de las bibliotecas públicas, para diagnosticar fortalezas y debilidades y diseñar propuestas formativas adecuadas.

- Conveniencia de trabajar de forma colaborativa, formando consorcios para generar mejores opciones, que afronten la escasez y los recortes presu- 
puestarios que viven las bibliotecas públicas en determinados países, regiones y/ciudades, ante la situación económica mundial o los diferentes niveles de desarrollo e inversión en educación y cultura. A su vez, sería conveniente trabajar unidos con otros tipos de bibliotecas, como testimonian las palabras de M. ${ }^{a}$ Begoña Marlasca (2012), directora de la BPE de Cuenca: "Echo de menos un mayor compromiso y cooperación entre las bibliotecas públicas respecto a su acción formativa, una ayuda más directa por parte de nuestros colegas universitarios, que han caminado por delante de nosotros, y una mayor concienciación entre las redes de bibliotecas, porque este ha de ser un trabajo compartido en red".

Algunos de estas recomendaciones ya han sido puestas de manifiesto por la IFLA (Lau, 2006) y por el Grupo de Trabajo de Alfabetización Informacional (2009), pero especialmente queremos enfatizar dos aspectos cruciales: de un lado, la promoción de la concienciación sobre alfabetización informacional de las autoridades nacionales, regionales y locales, instituciones educativas, profesionales de la información y usuarios, fomentando la colaboración y coordinación entre los distintos tipos de bibliotecas para el desarrollo de iniciativas sostenibles. Y de otro, el establecimiento de evidencias e indicadores de alfabetización informacional que ayuden a las instituciones a identificar su nivel de incorporación (Uribe-Tirado, 2010) y a mejorar su desarrollo, para conocer hasta qué punto los ciudadanos son capaces de participar en la sociedad del conocimiento (Catts y Lau, 2008).

\section{Prospectiva}

En relación con el futuro de la biblioteca pública, ésta tiene el gran reto de sobrevivir en un mar de información electrónica creciente y dispersa, debiendo satisfacer las demandas de los nuevos usuarios nacidos con Internet, cómodos con la tecnología, que aseguran ser independientes en cuanto a la búsqueda y recuperación de información. No obstante, se evidencian carencias significativas en los aspectos relacionados con el procesamiento cognitivo de la información, esto es, su análisis, síntesis, evaluación y uso. Para afrontar estas debilidades, la biblioteca tendrá que potenciar aún más su dimensión formativa, repensando su modelo de funcionamiento y sus servicios para adecuarlos a la filosofía integradora 2.0 y a los siguientes requerimientos:

- Será ubicua, estará en cualquier parte.

- Precisará de una redefinición en sus servicios como recurso virtual no limitado por el tiempo y el espacio.

- Será abierta y accesible, no pondrá barreras entre la información y el usuario. En todo caso, mejorará su labor de intermediación. 
- Invitará a la participación y a la colaboración de los usuarios, contribuyendo a su empoderamiento.

- Utilizará sistemas de información flexibles y ofrecerá servicios Web personalizados e interoperables.

\section{Conclusiones}

Este trabajo muestra cómo el tema de la alfabetización informacional en las bibliotecas públicas desde el contexto iberoamericano se encuentra en fase incipiente de desarrollo, considerando que son pocos los casos donde hay programas formales de ALFIN, con la planificación estratégica y pedagógica que una biblioteca pública debe tener para el desarrollo adecuado de sus servicios de formación.

En esos casos, algunos siguen realizando una formación bastante convencional (basada en didácticas presenciales), aunque otros han comenzado a incluir nuevas metodologías, entre las que destaca el uso de la Web 2.0. En base a la ecuación propuesta, es necesario insistir simultáneamente en los dos componentes principales: formar-formarse en ALFIN con los recursos 2.0, y formarformarse en competencias informacionales, y a su vez, diferenciar la formación en competencias digitales (alfabetización digital) y competencias informacionales (ALFIN).

En realidad, algunas bibliotecas públicas han hecho un esfuerzo creciente para aglutinar la trilogía ALFIN, Web 2.0 y e-ALFIN 2.0, pero hemos de reconocer que aún falta bastante por hacer para una gran mayoría de instituciones bibliotecarias. Pero lo importante y valioso es que hay un camino que ha comenzado a recorrerse en dirección hacia la biblioteca hibrida, con el diseño y desarrollo de programas de ALFIN bíbridos que responden a las necesidades de información y a las posibilidades y potencialidades formativas de sus usuarios bíbridos.

\section{Bibliografía}

ACRL/ALA (2003). Características de los programas de alfabetización en información que sirven como ejemplo de las mejores prácticas. Boletín de la Asociación Andaluza de Bibliotecarios (70), 67-72. http://www.aab.es/pdfs/baab70/70a4.PDF [consultado: 18-05-2011].

Alvarez Massó, M. (2012). BP como centro de aprendizaje abierto. Veintitantas experiencias ALFIN y una canción esperanzada: Monográfico sobre Alfabetización Informacional. ALFARED (Homenaje a la revista Educación y Bibliotecas). http://www.alfared.org/sites/www.alfared.org/files/u49/22-bibliotecap\%C3\%BAblica.MONTSERRAT. BARCELONA.pdf [consultado: 1-12-2011]. 
Amândio, M. J. (2007). Literacia de Informação 2.0 nas Bibliotecas Municipais de Oeiras: uma abordagem ao Programa Copérnico. http://www.slideshare.net/MJA/literacia-deinformao-20-nas-bmo-uma-abordagem-ao-programa-coprnico [consultado: 25-10-2011].

Amândio, M. J. (2009). Literacia de informação nas Bibliotecas Municipais de Oeiras: a busca do sentido na cultura digital. European Conference on Reading e no $1^{\circ}$ Forum Ibero-Americano de Literacias, Braga.

Basili, C. (2003). Information Literacy in Europe: a first insight into the state of the art of information literacy in the European Union. Roma: Consiglio Nazionale delle Ricerche. $315 \mathrm{p}$.

Basili, C. (2004). En Il survey. Roma: Consiglio Nazionale delle Ricerche. http://www.ceris. cnr.it/Basili/EnIL/questionnaire.html [consultado: 1-12-2011].

Basili, C. (2008) Information Literacy at the crossroad of Education and Information Policies in Europe. Roma: Consiglio Nazionale delle Ricerche, 301 p.

Basili, C. (2009) The Observatory on Information Literacy Policies and Research in Europe. Roma: Consiglio Nazionale delle Ricerche, 413 p.

Bawden, D. (2001) Progress in Documentation-Information and Digital Literacies: A Review of Concepts. Journal of Documentation (57), 218-59.

Bawden, D. (2002) Revisión de los Conceptos de Alfabetización Informacional y Alfabetización Digital. Anales de Documentación (5), 362-408.

Behrens, S. J. (1994). A Conceptual Analysis and Historical Overview of Information Literacy. College and Research Libraries, 55.

Bruce, C.; Edwards, S., y Lupton, M. (2006). Six Frames for information literacy education: exploring the challenges of applying theory to practice. ITALICS Special issue. Information literacy - the challenges of implementation. http://www.ics.heacademy. ac.uk/italics/vol5-1/pdf/sixframes_final\%20_1_.pdf [consultado: 14-08-2011].

Calixto, J. A. (2003). Literacia da informação: um desafio para as bibliotecas. Homenagem ao Professor Doutor José Marques, Faculdade de Letras da Universidade do Porto. http://ler.letras.up.pt/uploads/ficheiros/artigo5551.PDF [consultado: 25-10-2011].

Castillo Fernández, J. (2012). Últimas experiencias ALFIN BR de Murcia. Veintitantas experiencias ALFIN y una canción esperanzada: Monográfico sobre Alfabetización Informacional. ALFARED (Homenaje a la revista Educación y Bibliotecas). http://www. alfared.org/sites/ - www.alfared.org/files/u49/18-ultimasexperienciasMURCIA.pdf [consultado: 11-01-2012].

Catts, R.; Lau, J. (2008). Hacia unos indicadores de Alfabetización informacional. Paris: UNESCO. http://wikialfin.pbworks.com/f/IndicadoresAlfinUNESCOborrador $\% 5$ B1\%5D.pdf [consultado: 2-07-2011].

Cesarini, P. (2004). Computers, Technology, and Literacies. Journal of Literacy and Technology, 4(1).

Correia, A. M.; Teixeira, J. (2003). Information literacy for a safer Internet. Information Review, 27(5).

CILIP-Chartered Institute of Library and Information Professionals. (2004). Alfabetización en información: la definición de CILIP (UK). Boletín de la Asociación Andaluza de Bi- 
bliotecarios (77), 79-84. http://www.aab.es/pdfs/baab77/77a4.pdf [consultado: 22-082011].

Cuevas Cervero?, A. (2007). Lectura, alfabetización en información y biblioteca escolar. Gijón: Ediciones TREA.

Fino Garzón, D. M. (2010). Alfabetización Informacional en la Red Capital de Bibliotecas Públicas de Bogotá. BiblioTic 2010. Segundo Encuentro de Bibliotecas en Tecnologías de la Información y la Comunicación. http://www.slideshare.net/colaboratorio/bibliotic2010-bibloredalfin20 [consultado: 25-10-2011].

Fino Garzón, D. M.; Valderrama Espejo, I. (2010). Modelo de Taller en Alfabetización Informacional 2.0 para la formación de ciudadanos digitales en la Franja Infantil de la Biblioteca Pública El Tintal Manuel Zapata Olivilla. Congreso INFO-Cuba. http://www.infolitglobal.info/directory/en/resources/open/document/1895?f=9.FINO_ GARZ\%C3\%93N,_DIEGO_MAURICIO_INFO2010.doc [consultado: 25-10-2011].

García Gómez, F.; Díaz Grau, A. (2007). Formación de usuarios y Alfabetización informacional: dinámicas de trabajo en bibliotecas públicas. Acción pedagógica en instituciones artísticas y culturales. Grupo Xabide, 215-247. http://eprints.rclis.org/bitstream/10760/10694/1/FU_ALFIN_BPxabide.pdf [consultado: 25-10-2011].

González Fernández-Villavicencio, N. (2008). ALFIN 2.0. Taller UNESCO para formación de formadores en ALFIN, Granada. http://medina-psicologia.ugr.es/biblioteca/course/ view.php?id=3 [consultado: 14-05-2011].

Gómez-Hernández, J. A. (2007). Alfabetización informacional. Cuestiones básicas. Anuario ThinkEPI 2007. pp.43-50. http://eprints.rclis.org/bitstream/10760/8743/1/AnuarioThinkEPI-2007-Gomez-Hernandez-Alfin.pdf [consultado: 22-08-2011].

Gómez-Hernández, J. A. (2009). Aprender a enseñar competencias informacionales a los usuarios: avances en la formación profesional en España. Anuario ThinkEPI 2009, 106113. http://www.thinkepi.net/aprender-a-ensenar-competencias-informacionales-a-losusuarios-avances-en-la-formacion-profesional-en-espana [consultado: 22-08-2011].

Gómez-Hernández, J. A.; Pasadas-Ureña, C. (2007): La alfabetización informacional en bibliotecas públicas. Situación actual y propuestas para una agenda de desarrollo. Information Research, 12(3). http://informationr.net/ir/12-3/paper316.html [consultado: 13-12-2011].

Goulding, A. (2004). Libraries and social capital. Journal of Librarianship and Information Science, 36(1), 3-6.

Grassian, E. S.; Kaplowitz, J. R. (2009). Information literacy instruction. Theory and practice (Second edition). New York: Neal-Schuman Publishers. 412 p.

Grupo de Trabajo de Alfabetización informacional del Consejo de Cooperación Bibliotecaria (2009). Hacia la alfabetización informacional en las bibliotecas públicas españolas. Madrid: CCB. 56 p. http://www.mcu.es/bibliotecas/MC/ConsejoCB/gt_alfin/ ALFIN_en_BP_2009.pdf [consultado: 5-11-2011].

Hilbun, J.; Akin, L. (2007). E-Mentoring for Librarians and Libraries. Texas Library Journal, 1 (83), 29-32.

Lau, J. (2006). Comité Presidencial para la agenda internacional sobre el aprendizaje a lo largo de la vida. Informe final. International Federation of Library Institutions and 
Associations. http://app.cepcastilleja.org/contenido/ccbb/saber_mas/otros/8_alfabetizacion_inf_ifla.pdf [consultado: 3-06-2011].

Lau, J. (comp.) (2007). Information Literacy: An international state-of-the art report. UNESCO-IFLA. http://www.infolitglobal.info/media/UNESCO_IL_state_of_the_art_report__Draft070803.doc [consultado: 3-06-2011].

Li, L.; Liren, G.; Zhaoxia, X. (2009). Building satisfaction model for information users base don perceive quality of academic database Websites. Journal of the China Society for Scientific and Technical Information, 28(4), 524-530.

Marlasca Gutiérrez., M. B. (2012). El plan de formación en la BPE de Cuenca. Veintitantas experiencias ALFIN y una canción esperanzada: Monográfico sobre Alfabetización Informacional. ALFARED (Homenaje a la revista Educación y Bibliotecas). http://www.alfared.org/sites/ - www.alfared.org/files/u49/19-planformaci\%C3\%B3nCUENCA.pdf [consultado: 11-01-2012].

Marzal, M. Á.; Calzada Prado, J. (2007). 15 años de alfabetización en información: investigación internacional recogida en LISA, ERIC y SSCI entre 1990 y 2005. Boletín de la Asociación Andaluza de Bibliotecarios (86-87), 15-27. http://www.aab.es/pdfs/baab8687/86-87a1.pdf [consultado: 18-07-2011].

Ministerio de Cultura. Subdirección General de Coordinación Bibliotecaria (2006). Declaración de Toledo. Bibliotecas por el aprendizaje permanente. http://www. Webcitation.org/5NrAiGhSS [consultado: 1-11-2010].

ONU (2000). Década de la Alfabetización de Las Naciones Unidas. http://unesdoc.unesco.org/images/0013/001336/133672s.pdf [consultado: 1-11-2010].

Ortega Vaquero, I; González Fernández-Villavicencio, N. (2012). Veintitantas experiencias ALFIN y una canción esperanzada: Monográfico sobre Alfabetización Informacional. ALFARED (Homenaje a la revista Educación y Bibliotecas). http://www.alfared.org/ sites/ - www.alfared.org/files/u49/01-planALBA.pdf [consultado: 11-01-2012].

Pasadas-Ureña, C. (2006). Alfabetización Informacional. Mesa redonda sobre alfabetización informacional y bibliotecas públicas. En: III Congreso Nacional de Bibliotecas Públicas, Murcia, 179-185. http://eprints.rclis.org/bitstream/10760/10136/1/actas_congreso3bp. pdf [consultado: 25-10-2011].

Peñalver Martínez, Á.; Gallo León, J. P. (2006). Bibliotecas públicas: de la formación de usuarios a la alfabetización informacional, Biblioteca Regional de Murcia, 1996-2006. Educación y Biblioteca (156), 101-106.

Pinto, M. (2010). Design of the IL-HUMASS survey on information literacy in higher education: a self-assessment approach. Journal of Information Science, 36(1), 86-103.

Pinto, M.; Cordón, J. A.; Gómez, R. (2010). Thirty years of information literacy (19772007): A terminological, conceptual and statistical analysis. Journal of Librarianship and Information Science, 42(1), 3-19.

Pinto, M.; Sales, D.; Osorio, P. (2008). Biblioteca universitaria, CRAI y alfabetización informacional. Gijón: Ediciones TREA, 245 p.

Pinto, M.; Sales, D., Osorio, P.; Planelles, E. (2009): Alfabetización múltiple desde la biblioteca pública: experiencias y propuestas. Buenos Aires: Alfagrama Ediciones, 224 p. 
Pinto, M.; Uribe-Tirado, A. (2011). Formación del bibliotecario como alfabetizador informacional. Anuario Thinkepi, Barcelona, 2011.

Pinto, M.; Uribe-Tirado, A.; Cordón, J. A.; Gómez Díaz, R. (2011) La producción científica internacional sobre competencias informacionales e informáticas: tendencias e interrelaciones. Información, Cultura y Sociedad. Revista del Instituto de Investigaciones Bibliotecologicas-Argentina (25), 29-62.

Prades Ginovart, I. (2012). Sumamos voces: biblioteca sin barreras. Veintitantas experiencias ALFIN y una canción esperanzada: Monográfico sobre Alfabetización Informacional. ALFARED (Homenaje a la revista Educación y Bibliotecas). http://www. alfared.org/sites/ - www.alfared.org/files/u49/16-Biblioteca\%20Marcelli.pdf [consultado: 11-01-2012].

Rader, B. (2002). Information literacy 1972 - 2002: A selected literature review. Library Trends, 51(2), 242-260.

Saumell i Calaf, D. (2006). La experiencia ALFIN de la Biblioteca Pública de Tarragona. En: Congreso Nacional de Bibliotecas Públicas (3. ${ }^{\circ}, 2006$, Murcia). La biblioteca pública, espacio ciudadano: Actas III Congreso Nacional de Bibliotecas Públicas, Murcia, 29-30 de noviembre y 1 de diciembre. Madrid: Ministerio de Cultura, Subdirección General de Información y Publicación, 2006, pp. 170-178. Recuperada el 2 de febrero de 2012 de: http://hdl.handle.net/10421/664

Saumell Calaf, D.; Gondolbeu Solé, N.; Calduch Forastero, C. (2012). Fórmate para encontrar trabajo desde la Biblioteca. Veintitantas experiencias ALFIN y una canción esperanzada: Monográfico sobre Alfabetización Informacional. ALFARED (Homenaje a la revista Educación y Bibliotecas). http://www.alfared.org/sites/www.alfared.org/files/ u49/27-tarragona_0.pdf [consultado: 11-01-2012].

SCONUL (2004). Learning Outcomes and Information Literacy. London: Higher Education Academy. http://www.heacademy.ac.uk [consultado: 5-11-2011].

Spitzer, K. L.; Eisenberg, M. B.; Lowe, C. A. (1998). Information Literacy Essential Skills for the Information Age. Syracuse, NY: ERIC Clearinghouse on Information \& Technology, Syracuse University. http://www.eric.ed.gov/ERICWebPortal/search/detailmini.jsp?_nfpb=true\&_\&ERICExtSearch_SearchValue_0=ED427780\&ERICExtSearch_Search Type_0 $=$ no\&accno=ED 427780 [consultado: 1-1-2011].

Stripling, B. (2006). La alfabetización informacional y las bibliotecas públicas en Estados Unidos. III Congreso Nacional de Bibliotecas Públicas, Murcia, 197-203. http://eprints. rclis.org/bitstream/10760/10136/1/actas_congreso3bp.pdf [consultado: 25-10-2011].

Town, J. S. (2002). Information Literacy: Definition, Measurement and Impact. ITEILit 2002 - 1st International Conference on IT \& Information Literacy. Glasgow, March 2002.

UNESCO (2003) Declaración de Praga sobre Alfabetización Informacional: Hacia una sociedad informacionalmente alfabetizada. http://www.eubca.edu.uy/materiales/servicio_de_informacion_y_consulta/praga.pdf [consultado: 1-11-2011].

UNESCO (2005) Declaración de Alejandría sobre Alfabetización Informacional: Faros para la Sociedad de la Información. http://www.ifla.org/III/wsis/BeaconInfSoc-es.html [consultado: 1-11-2011]. 
Uribe-Tirado, A. (2010). La Alfabetización Informacional en la Universidad. Descripción y Categorización según los Niveles de Integración de ALFIN. Caso Universidad de Antioquia. Revista Internamericana de Bibliotecologia, 33(1), 31-83. http://eprints.rclis. org/bitstream/10760/14231/1/ALFIN_EN_LA_UNIVERSIDAD.pdf [consultado: 13-102011].

Uribe-Tirado, A. (2012a). Empleo de las tecnologías en los programas de alfabetización informativa. Tarango, J. (comp). Didáctica básica de la alfabetización informativa. Buenos Aires: Alfagrama Ediciones (en proceso de edición).

Uribe-Tirado, A. (2012). Veintitantas experiencias ALFIN y una canción esperanzada: Monográfico sobre Alfabetización Informacional compilado por Felicidad Campal (Homenaje a la revista Educación y Bibliotecas). http://www.alfared.org/content/veintitantas-experiencias-alfin-y-una-canci-n-esperanzada/1287 [consultado: 11-01-2012].

Vilanova, N. (2012). Biblioteca Salvador Estrem i Fa. Veintitantas experiencias ALFIN y una canción esperanzada: Monográfico sobre Alfabetización Informacional. ALFARED (Homenaje a la revista Educación y Bibliotecas). http://www.alfared.org/sites/ www.alfared.org/files/u49/04-bibliotecasalvadorestremifa.pdf [consultado: 11-01-2012].

Virkus, S. (2003). Information Literacy in Europe: A Literature Review. Information Research, 8(4). http://informationr.net/ir/8-4/paper159.html [consultado: 3-8-2011].

Webber, S. (2006). Information Literacy in Higher Education. En: Stopar, K. and Rabzelj1 (eds). Information Literacy between theory and practice: The role of academic and special libraries: Proceedings. Ljubljana: ZBDS, 9-20. 